that future friends of aviation will discover means for advancing its development that will not tempt men to repeat such dangerous adventures as were inevitably associated with the London to Manchester flight, and that M. Paulhan's success will not stimulate a number of less experienced followers to attempt to emulate his achievement.

G. H. Bryan.

THE FIGHT AGAINST SLEEPING SICKNESS. ${ }^{1}$

(I) THE report of the German Sleeping Sickness Commission is an attractive work in which even those who are not specially concerned with the problems of sleeping sickness may find much to interest them. In addition to a great mass of detail bearing on the etiology, diagnosis, treatment, and prevention of a disease which is at present the most important economic problem of European administrations in Africa, the work contains many facts and observations of interest to the naturalist and the anthropologist, and is illustrated by numerous exquisite photographs. A certain number of the illustrations have, as might be expected in a work of this kind, a melancholy interest, representing the ravages of the disease as shown by sufferers from it, or even more significantly by deserted homesteads; but others give a vivid idea of the scenery of the shores of the Victoria Nyanza and of the dwellings, habits, and appearance of the natives of that region.

After a brief introduction and an account of the general course of the expedition, by Dr. Koch, there follow sections on the etiology of sleeping sickness, by Dr. Koch; on diagnosis and on clinical observations, by Prof. Beck; on the treatment of the disease, by Prof. Beck and Prof. Kleine; and on preventive measures, by all three authors. In an appendix are to be found meteorological observations made during the expedition, and a history of 180 cases of sleeping sickness that came under observation and treatment, with their temperature charts.

The section on etiology is divided into two parts, dealing respectively with Trypanosoma gambiense and Glossina palpalis. Trypanosomes were found not infrequently in the blood of persons whose glands did not show the characteristic swellings and who presented no symptoms of disease. The number of trypanosomes in the blood of infected persons was always small, and appeared to be subject to periodic variations. In the lymphatic glands trypanosomes were more numerous than in the blood. It is stated that the trypanosomes in the blood were always uniform in appearance, and showed no differentiation of form; but all preparations seem to have been made by methods which, though suitable for clinical diagnosis, were quite inadequate for accurate study of structural details.

Many animals were examined with the object of discovering a vertebrate host other than man for Trypanosoma gambiense. Of mammals, only in a single monkey were trypanosomes found, similar in type to T. gambiense; those found in birds, on the other hand, were of a distinct type. In reptiles, trypanosomes were found in tortoises and crocodiles. The trypanosome of the crocodile is described as large, and similar in appearance to the European $T$. rota-

1 (I) Bericht über die Tätigkeit der zur Erforschung der Schlafkrankheit im Jahre rgo6-7 nach Ostafrika entsandten Kommission. Erstattet von Dr. R. Koch, Prof. Dr. M. Beck, and Prof. Dr. F. Kleine. Pp. vi +323 ;
5 plates. (Berlin: Julius Springer, rgog.) Price r6.40 marks.

(2) Bibliography of Trypanosomiasis. Compiled by C. A. Thimm. Pp. iv +228 . (London: Sleeping Sickness Bureau, Royal Society, rgog.) Price $4 s . ;$ to be obtained from the Bureau.

(3) Sleeping Sickness Bureau, Bulletin No. r3. Vol. ii., January. (London: Royal Society, 19ro.)

(4) Report on the Measures adopted for the Suppression of Sleeping Sickness in Uganda. By Sir Hesketh Bell, K.C.M.G. Colonial Reports.Miscellaneous, No. 65, December, rgog. Pp. 27, 1 map. NO. 2 I I 4, VOL. 83] torium of frogs. In view of the erroneous statements that have been so often made, attributing to Dr. Koch the discovery of a connection between sleeping sickness and crocodiles (see Nature, February 18, I909, p. 458), attention should be directed to his clear statement that " in any case there is no connection between this crocodile-trypanosome and Trypanosoma gambiense."

With regard to the transmission of $T$. gambiense, Dr. Koch believes it to be effected by Glossina palpalis alone. Nearly three thousand tsetse-flies of this species were examined, and 189 of them were found to contain trypanosomes, of which four types are distinguished and described with the aid of coloured figures drawn from stained preparations. Three of these types of "wild" trypanosomes are considered to be distinct from $T$. gambiense, with which species, however, "Type IV." is identified; it was found five times in tsetses caught on the Sese Islands. "Type I.," the commonest of the four types in occurrence, is identified with the trypanosome of the crocodile. Attempts were made to infect tsetse-flies with $T$. gambiense by feeding them on infected animals, but in all cases the trypanosomes died out in a few days in the alimentary tract of the Glossina. The infection of the tsetse-fly can only be brought about, it is suggested, under certain definite but as yet unknown conditions. The more recent work of Prof. Kleine and Sir David Bruce will doubtless, when completed, make clear the nature of these conditions and solve a problem which has baffled previous investigators.

A number of observations upon the habits of Glossina palpalis are set forth. Dr. Koch is of opinion that crocodile-blood is the principal food of this fly, but that other animals also contribute to its nourishment, especially the hippopotamus. Experiments were made on the effects of clearing the vegetation in spots haunted by the fly, with results confirmatory of the experience of others, that this is an effective method of banishing the fly.

At the beginning of the section dealing with etiology in this report, Dr. Koch points out that the more important facts bearing upon this subject have already been made known by the work of others, and that consequently the investigations of the German Commission can only pretend to fill some gaps and contribute towards "completion of the etiology." It is doubtless for this reason that Dr. Koch so seldom mentions the results of other investigators in his account of his own observations, and often writes in a manner which might lead those unacquainted with previous work on the subject to think that his observations were new. As a matter of fact, the only discovery which can be claimed by Dr. Koch and his collaborators as entirely original, so far as the etiology of sleeping sickness is concerned, is that of the occurrence of trypanosomes in the salivary glands of the tsetse-fly. This important discovery, which was first announced in a preliminary communication to a German medical periodical in 1907 , had not been made previously by any investigator, and was received at first with some scepticism, but has since been confirmed by Prof. Kleine and Sir David Bruce.

Prof. Beck's section on the diagnosis of sleeping sickness deals in turn with gland-puncture, lumbar puncture, and blood-investigation. The last of these methods is considered the surest when carried out in a manner which was employed by the Commission, and is described in detail; it is stated to have often given positive results when other indications were negative, especially in those cases in which the glands had become normal under treatment. 
With regard to the treatment of sleeping sickness, Prof. Beck deals with the use and effects of atoxyl, and Prof. Kleine with those of other drugs, of which a variety were tried, but with results inferior to those yielded by atoxyl. For combating sleeping sickness Dr. Koch lays stress on the importance of discovering the infected persons in the earliest stages of the disease, both because curative treatment has then most chance of success, and also in order to prevent them from spreading the infection. The treatment should be carried out in concentration camps situated in places free from tsetse-flies. Healthy populations snould be hindered from access to the lake-shore except at places cleared of the vegetation which shelters the tsetses, and the collection of rubber should be forbidden so long as there is danger of infection in the forests on the shore. The tsetse-flies should be kept in check by clearing vegetation in their haunts and by destroying the crocodiles, their principal food supply; this object is to be effected by encouraging the destruction of the nests and eggs of these reptiles. In view of the voracity of tsetse-flies and the readiness with which they suck the blood of any vertebrate animal, it may well be doubted whether the extirpation of crocodiles, though very desirable for many reasons, if practicable, would have the desired effect of diminishing the numbers of the flies to any appreciable extent.

(2) The bibliography of trypanosomiasis issued by the Sleeping Sickness Bureau is a labour-saving publication that will be most useful to those occupied with any problems, whether medical or scientific, relating to trypanosomes and their hosts, vertebrate or invertebrate. It aims at being complete up to March 3I, I909, and contains references, alphabetically arranged, to about 1900 original memoirs, articles, and treatises, catalogued under the authors" names, and numbered in order. In addition to these numbered references, the titles of journals that contain literature on trypanosomes or tsetse-flies are inserted without numbers, followed by a list of the articles or memoirs they contain, so that it is possible to look up the title of a journal in the catalogue and find what papers on trypanosomes or tsetses have been published in it. It is stated that a subject-index is in course of preparation, to be issued as a supplementary pamphlet, indicating the numbers in the bibliography to be consulted for the various subjects.

(3) The thirteenth Bulletin of the Sleeping Sickness Bureau begins a second volume of this most useful publication. Amongst other subjects, the present number deals with the transmission of trypanosomes, the treatment of trypanosome-infections, methods of destroying tsetse-flies, and the alleged occurrence of "ultra-microscopical" forms of trypanosomes. An interesting account is given of a method of destroying tsetse-flies, discovered by $\mathrm{Mr}$. Maldonado, manager of an estate on the island of Principe, who observed that these flies attacked the backs of labourers stooping at their work in the fields; he caused the labourers to wear on their backs black cloths coated on the outer surface with a glutinous substance. In this way 133,778 tsetse-flies were trapped on one plantation during some twenty months. This method may be found useful, it is suggested, for keeping down Glossina palpalis in places where clearing is impracticable. A very useful feature of the Bulletin is a section entitled "Sleeping Sickness News," in which information is given concerning recen ${ }^{+}$developments of the disease and measures taken to check it.

(4) Sir Hesketh Bell gives a historical account of the progress of discovery and research, and a summary of the results gained, with regard to sleeping sickness. He then describes the administrative measures taken in Uganda to combat the disease. These measures may be summarised as follows:(I) The removal of infected persons into fly-free areas, that is to say, more than two miles away from the lake-shore, in order that they shall not render the tsetse-flies infective and capable of transmitting the disease to healthy persons; for this purpose segregation camps have been started in which those afflicted with the disease are put under medical treatment; (2) the removal of healthy persons from areas infested by tsetse-flies, until such time as the flies may be supposed to have lost their infectivity; (3) the extirpation or banishment of the fly, by clearing the forest on the foreshore of Lake Victoria, in those places, such as ferries or ports of main trade-routes, fron which it is not practicable to remove the population. The task of keeping the foreshore clear is stated to have been aided greatly by planting the cleared areas with citronella-grass, which grows rapidly, and is also of commercial value, yielding ai considerable amount of valuable oil.

These measures, when first planned, were based on the belief that the tsetse-fly only transmitted the disease mechanically and did not remain infective for a longer period than forty-eight hours, a belief founded on the experimental results of scientific investigations which had at that time demonstrated clearly the existence of so-called "direct" or "mechanical" infection, but had failed to obtain evidence for the occurrence of deferred or "cyclical" transmission. Consequently it was thought that the flies would lose their infectivity very quickly when they could no longer suck the blood of diseased persons. The recent researches of Kleine and Bruce, however, have shown that the trypanosome of sleeping sickness goes through a developmental cycle in the tsetse-fly, and that when once the trypanosome has established itself, the fly remains infective, apparently for the rest of its life, without again feeding on the blood of an infected person. It follows from this discovery that the period for which healthy persons must be removed from the fly-belts, in order to ensure that the infection has died out in the flies, is much longer than was thought, and cannot at present be stated definitely. There are two further possibilities to be borne in mind, neither of which have as yet been proved, though often suspected, to exist, and which greatly complicate the problem of the transmission and spread of the disease. One is that an infected tsetse-fly may transmit the infection to its offspring; the other, that some vertebrate animal other than man may harbour the trypanosome of sleeping sickness in its blood, and so be a "reservoir-host" which keeps up the infection in the flies. It must also be remembered that to keep the natives, probably much against their inclinations in many cases, more than two miles from the shore along the immense coast-line of the Victoria Nyanza must be a task of considerable difficulty and of uncertain result. The natives concerned are evicted from the homes which they and their ancestors have inhabited for untold generations, and, moreover, they are for the most part extremely sceptical as to the agency of the tsetse-fly in the transmission of the disease. It is therefore extremely probable that in spite of administrative prohibitions, leakage, so to speak, sometimes occurs, and natives evade the regulations against frequenting the danger zone. In a recent communication to the Royal Society (vide Proceedings, r909) Bruce and his collaborators state that they have found tsetse-flies still infective that were caught in localities from which the natives had been removed, and conclude that the tsetse-flies "can retain their 
infectivity for a period of at least two years after the native population has been removed." Whether this very discouraging result is to be explained by longevity of the flies, by hereditary transmission of the trypanosomes in the flies, by the existence of "reservoir" hosts, or by leakage and transgression of official orders, cannot be decided positively at present. Time alone can show if the measures adopted will be efficacious in stamping out the disease and the result will be awaited anxiously by all who have the interests of our African colonies at heart.

E. A. M.

\section{DEVELOPMENT OF UNIVERSITY (AND OTHER) EDUCATION IN INDIA.}

THE recent publication of the "Fifth Quinquennial Review of the Progress of Education in India, x902-7," by Mr. H. W. Orange, C.I.E., Director General of Education in India, indicates clearly that very considerable and satisfactory progress is being made in India in all branches of education, and that the university standards in particular are being raised and made more real and effective. The review deals with the period I902-7, and it is probable that during no previous five years has there ever been such rapid and sound progress.

The best indication of the increased amount of attention which education is securing will be found in the expenditure, which is mainly met from public funds. Thus in I902 the total expenditure on education in India was 40I lakhs of rupees, while in 1907 it had advanced to 559 lakhs, or an increase of nearly 40 per cent. This increased expenditure has been accompanied by a very large increase in the number of pupils in all stages and branches of education. Thus there were nearly I200 more pupils studying university courses, nearly 77,000 more secondary school pupils, and about 860 ,0oo more primary school pupils under instruction in the year 1907 than there were five years previously. In certain cascs much more progress was made in the five years, I $002-7$, than had been made in the previous fifteen vears. This is specially the case in the matter of training of teachers, in female education, in the special education of Mohammedans, and in the primary standards for boys generally, of whom, of course, the great majority are Hindus. These are all very healthy signs, and perhaps the first and second named may be considered as of almost vital importance to the satisfactory progress of Indian education and of India as a nation.

These great improvements have been mainly brought about by the fact that, under Lord Curzon's government as Viceroy, a general inquiry was held which extended to all kinds and grades of educational institutions, from the universities to the primary schools. This inquiry brou!sht under examination the methods, organisation, tendencies, and results of Indian education as a whole, and resulted in the meeting of various committees, conferences, and commissions. As the result of these, certain general lines of policy were laid down by the Imperial Government, and these have since been continuously applied by the various local governments and authorities in meeting the local educational needs of the various provinces.

In the case of university education in India, a good deal of leeway had and still has to be made up. In many cases standards of teaching had become antiquated, and were also unsuitable. In previous vears a great many art colleges had been started by persons wishing to help forward the great cause of

1 Published in Calcutta by the Superintendent of Government Printing in India, Igog.

$$
\text { NO. } 2 \text { II } 4 \text {, VOL. 83] }
$$

education, and these had been affiliated to the various universities. Many of these were known to be insufficiently staffed and very imperfectly equipped generally, the main cause for such conditions being the exceedingly slender financial resources of these institutions. This has been due to their having no endowments and to the exceedingly small fees charged to the students, an annual fee of two to three pounds being commonly paid by a student for education up to B.A. and M.A. standards. Added to this, many colleges were endeavouring to teach a great variety of subjects instead of confining their attention to one or more simple courses, which could have been efficiently carried through with the means at their disposal. As a result of these conditions, a considerable proportion of the students sent up for examination had only received an imperfect training, and this state of affairs having gone on for a considerable period, it had almost insensibly reacted on the standards of the examinations themselves, which had become much lower than was desirable.

To remedy this state of affairs, after certain preliminary inquiries a University Commission was appointed which exhaustively examined into university education in all parts of India, and this reported in June, 1902. As a result a new Act was passed early in 1904 which reconstituted the five existing universities. Under the previous Acts of Incorporation the work of the universities was confined practically solely to the examination of students, while the new Act declared that the universities were "incorporated for the purpose (among others) of making provision for the instruction of students, with power to appoint university professors and lecturers, to hold and manage educational endowments, to erect, equip, and maintain university laboratories and museums, to make regulations relating to the maintenance and conduct of students, and to do all acts which .... lead to the promotion of study and research."

This contrast shows the different aspect in which Indian universities are now being regarded, and these provisions will probably gradually exercise a powerful influence, though from their nature their effect can only come slowly, but even now, in certain branches of study, university courses of lectures are being delivered.

Certain other provisions also appear in the new Act which even in the short time which has elapsed since it was passed are having important and farreaching effects.

The senates were reconstituted, and steps were taken to make them more representative of those actually engaged in teaching in the affiliated colleges than had hitherto been the case, and appointments to the Senate were limited to five vears instead of for life. These new senates are now working much more efficiently that was formerly the case. Under the Act also. new sets of regulations had to be prepared for all branches of study, and the Government of India was given the power, after consulting the Senate, to make such additions and alterations as might be considered necessary. Speaking generally of the new regulations, they are a very great improvement on the old ones, for they require a much higher standard of study, and also that such study shall be practical rather than of a theoretical nature. Indeed, in all the science subjects practical work is made an essential part of the course of study, whereas formerly theoretical book-work frequently sufficed to carry a student successfully through some of the science examinations.

Perhaps, however, the clauses of the Act which are having the most immediate and tangible effect are those dealing with the affiliation of colleges to the 